\title{
Institucionalidad y gobernabilidad
}

\author{
René Fortín-Magaña' \\ Recibido: 12/12/2014 - Aceptado: 22/12/2014
}

\section{Resumen}

Para llegar a conclusiones aceptables sobre el tema que anuncia el presente artículo, hemos de partir de un proceso lógico que otorgue sólidos fundamentos a nuestra argumentación.

Así, podemos afirmar, sin vulnerar el juicio, que sin leyes no hay institucionalidad; sin institucionalidad no hay gobernabilidad; sin gobernabilidad no hay progreso; sin progreso no hay desarrollo; y sin desarrollo no hay significación nacional.

Pero el anterior es un polisilogismo abstracto que debemos aplicar a una situación concreta, verificando las conclusiones deducidas de premisas sobreentendidas. ${ }^{2}$

\section{Palabras clave}

Funcionarios públicos, democracia, estado de derecho, sistema democrático.

\section{Abstract}

In order to reach aceptable conclusions on the topic of this article, we have to start from a logical process that provides a solid ground to our argumentation.

Therefore, we can say-- without doing any harm-- that there is no institutionality without laws; if we do not have institutionality, there is no governability; if there is no governability, there is no progress; without progress, there is no development, and without development, there is no national significance.

But the above is an abstract polysyllogism that we shall apply to a concrete situation, verifying the conclusions that have been deducted from overstated premises.

\section{Keywords}

Public officials, democracy, the state of right, democratic system.

Decimos que sin leyes no hay institucionalidad porque sabemos de antemano, de acuerdo con nuestra Constitución, que nuestro país está organizado bajo un gobierno de normas jurídicas preestablecidas y no bajo los dictados de un hombre o un grupo de hombres. El dilema sobre este punto, que se viene discutiendo desde la antigüedad ("gobierno de leyes o gobierno de hombres"), ${ }^{3}$ está resuelto a favor del primer sistema, y no viene al caso

En nuestro país, El Salvador, en el año 2015 de la era cristiana, se conjuga tal cantidad de problemas que resulta lícito afirmar que se está viviendo una de las crisis más profundas. No es necesario recordar que una crisis es un punto de equilibrio que se constituye en atanor tanto para la degradación como para la superación.

\footnotetext{
Doctor en Jurisprudencia y Ciencias Sociales por la Universidad de El Salvador, René Fortín Magaña es abogado, notario y profesor. Fundador del Partido Acción Democrática; ha ocupado numerosos cargos, entre ellos, decano de la Facultad de Derecho, miembro de la Junta de Gobierno entre 1960 y 1961, y magistrado de la Corte Suprema de Justicia entre 1997 y 2006. Ha sido candidato a la presidencia de la República y diputado a la Asamblea General. Actualmente es director del Instituto de Investigación Jurídica de la Universidad Dr. José Matías Delgado.

Entimema.

3 Platón. El Estadista.
} 
demostrar por enésima vez su validez teórica, a pesar de los resabios existentes en el planeta.

La institucionalidad que proclamamos, por consiguiente, es la que está basada en un conjunto de leyes producto de la voluntad popular, titular de la soberanía, organizadas en pirámide, en cuya cúspide está situada la Constitución de la República.

Ahora bien, las leyes tienen un destinatario: el cuerpo social, sin excepciones, y son de obligatorio cumplimiento tanto para gobernantes como para gobernados. Pero para que este enunciado teórico se convierta en realidad y los destinatarios cumplan efectivamente las leyes, hacen falta dos condiciones: a) que las leyes sean consecuentes con la razón, la sociología y la historia, es decir, que sean justas y razonables, convirtiéndose así en derecho positivo, no en un enunciado virtual o en un instrumentos de la arbitrariedad; y b) que los destinatarios, anuentes al contrato social, estén dispuestos a cumplirlas (Rousseau, $\mathrm{s} / \mathrm{r}$ ).

Si los destinatarios, especialmente los funcionarios públicos, no acatan los dictados constitucionales y legales, se instalan el desorden, la anarquía y la ingobernabilidad.

Es verdad que un dictador puede establecer un orden, pero ese orden es precario y perecedero. Para que ese orden fuera digno de consideración, el dictador tendría que ser omnisciente, virtuoso, valiente, prudente, probo, visionario, competente y sobre todo, eterno, pues, de no ser así, al faltar la energía y la ecuanimidad de su larga mano, así pasaran cincuenta o cien años, que en términos históricos son un parpadeo, tornará la anarquía y podría reiniciarse el ciclo de que nos hablaba Aristóteles:

El gobierno de uno solo, basado en el interés general, se llama monarquía. El de algunos, sea cualquiera su número, con tal que no se reduzca a uno solo, se llama aristocracia, es decir, gobierno de los mejores, que debe tener por objeto el interés general de los asociados. EI de todos, cuando está combinado en vista de la común utilidad, toma el nombre genérico de los gobiernos, y se llama República. Tres son las desviaciones de estas tres formas de gobiernos: la tiranía, la oligarquía y la demagogia, que son respectivamente la degradación de la monarquía, de la aristocracia y de la República. Así, la tiranía es el gobierno de uno solo, que no tiene en cuenta sino el interés personal; la oligarquía es la supremacía de algunos en provecho de la clase a que pertenecen; y la demagogia es el abuso de la autoridad suprema en beneficio de los pobres. Ninguno de estos tres gobiernos tiene en cuenta para nada el interés general (Aristóteles, s/r).

Como diría Nietzsche, giraría la rueda de la historia en un "eterno retorno".

Por significativa que sea la clasificación del estagirita, no tenemos, sin embargo, que sentirnos aprisionados por el destino, como si todo obedeciera a un plan superior frente al cual se torna impotente la fragilidad humana. No. Más que creer que el destino marca la ruta del hombre, creemos que es el hombre quien construye su propio destino conjugando la libertad con la voluntad.

\section{Democracia representativa}

Dado que, por disposición constitucional, nuestro gobierno está basado en la democracia representativa ${ }^{4}$ con la sola excepción que autoriza la democracia participativa para promover la unión centroamericana ${ }^{5}$ procede determinar sí esa representación está bien ejercida y es capaz de producir buenas leyes, o si, por el contario, la cadena lógica se rompe en el primer eslabón.

Sobre este punto, nuestra observación cotidiana nos indica, como un hecho notorio, que tanto los instrumentos para la representación (sufragio) como la conducta cívica de la mayoría de los representantes del pueblo son deficientes. Y, si bien la Constitución ha otorgado a los partidos políticos la prerrogativa de ser "el único instrumento para el ejercicio de la representación del pueblo dentro del gobierno", 6 es con la condición de que se organicen de acuerdo con lo que la misma disposición establece: "Las normas, organización y funcionamiento se sujetarán a los principios de la democracia representativa", algo que está muy lejos de cumplirse en nuestro medio, en el cual las cúpulas de los partidos políticos actúan con una autonomía indebida, sin la menor objeción del Tribunal Supremo Electoral.

He aquí, pues, al comienzo de nuestro examen, una falla fundamental que habría que subsanar para dar inicio a una reingeniería institucional. Si no se cumple la Constitución y las leyes por los funcionarios públicos y los partidos políticos, quienes, para mayor declinación, hacen alarde de su desobediencia, mal podemos esperar una institucionalidad saludable.

\footnotetext{
${ }^{4}$ Constitución de la República de El Salvador, 1983, Art. 85, inciso primero: "El gobierno ex republicano, democrático y representativo".

${ }^{5}$ Ibídem. Art. 89 inciso último: "El proyecto y bases de la unión se cometerán a consulta popular".

${ }^{6}$ Ibídem. Art. 85 inciso $2^{\circ}$.

${ }^{7}$ Ibídem.
} 
Algo más: la grave falencia señalada es indicativa de una deplorable falta de cultura cívica. Pero he aquí que a los altos niveles de cultura se llega por la educación; y sabemos perfectamente que el método más eficaz para educar es el ejemplo. Si son los funcionarios públicos los que comienzan por dar el mal ejemplo, ¿cómo podemos exigirles a los sectores populares que sean fieles cumplidores de las normas morales, cívicas y jurídicas? ¿Que sean rectos? ¿Que sean probos? Hay en esto una terrible doble moral, una hipocresía, que se reduce a un discurso falaz: "Hagan lo que decimos pero no lo que hacemos". iCon qué vigor el apóstol José Martí condenaría esta moral perversa!

El mal ejemplo cunde, pues. Por eso debemos responsabilizar, en primer término, a los malos funcionarios que ha sufrido el país, cuya arbitrariedad, su desacato, su corrupción, su falta de pudor cívico, su ostentación, su saqueo de las arcas públicas, su soberbia, su codicia y su abandono del bien común se constituye en el principal componente criminógeno en el cual la gobernabilidad es tan precaria que no es una exageración hablar de un casi "Estado fallido", como ya ha sido calificado el nuestro por respetables observadores.

El progreso, por su parte, supone una conjunción de esfuerzos, tanto del sector público como del privado, que dentro de un orden respetable (una institucionalidad legítima) sepa combinar, con capacidad y dedicación, pensando en el interés general, los diversos factores de la producción. De no ser así, ¿cómo y cuándo saldremos de los infamantes títulos de países marginales y subdesarrollados que no tienen ninguna significación, ninguna, en el mundo globalizado y técnicamente avanzado de nuestros días? Un mundo que marca un porvenir insospechado, un horizonte inalcanzable para quienes no tengan el coraje de vivir y progresar conforme los cánones de la recta razón.

Las consideraciones anteriores están orientadas hacia la consecución de una meta que se ha venido persiguiendo desde la independencia de nuestro país, en 1821. Esto significa que por cerca de dos siglos, tropezando y levantándonos, hemos ido en pos de una esquiva utopía: el Estado Democrático Constitucional de Derecho, que, como los espejismos del desierto, más se desvanece cuando más nos aproximamos a él. Cuatro constituciones federales y trece constituciones nacionales dan fe de una línea zigzagueante.

Pero el caso es que, siguiendo la clasificación del tratadista de Derecho Constitucional Karl Loewestein, nuestras constituciones han estado muy lejos de ser normativas. En algunos casos han llegado a ser nominales. Pero en la mayoría de ocasiones han sido semánticas, es decir, juegos de abalorio, luces de bengala, disfraces al gusto del dictador de turno que han imposibilitado la aplicación del paradigma democrático que hace fuertes a los pueblos: los gobiernos de leyes, no de hombres; la vigencia de una institucionalidad eficaz; la rectitud de los gobernantes; y la general y constante educación del pueblo (Loewestein, s/r).

Los Acuerdos de Paz, suscritos el 16 de enero de 1992, proclamaron - una vez más - la vigencia del Estado de Derecho que quedó consagrado en la Constitución de 1983 y sus reformas de 1991 y 1992. Desde que se firmaron dichos acuerdos y se dio por decreto al FMLN, dominado por las FPL, calidad de partido político, su ascenso al gobierno era potencial. Luego, no tiene por qué extrañarnos que esa posibilidad se haya convertido en realidad, si bien tenemos que deplorar que ese ascenso se haya obtenido por medio de una imposición desmedida encabezada por el Presidente de la República, y con una actuación del TSE que, por lo menos, dejó perder una sustancial cantidad de "votos impugnados" que se quedaron en el vacío.

Poco a poco, sin embargo, lo que parecía una gran conquista se fue convirtiendo en una ilusión, en una burbuja, en un texto más, volcado hacia la retórica y no a la normatividad, con la salvedad de que, por primera vez en nuestra historia, la Sala de lo Constitucional de la Corte Suprema de Justicia ha realizado ímprobos esfuerzos por romper una perniciosa práctica marginal y ha colocado las cosas en su lugar.

La gran paradoja, sin embargo, es que, a pesar de los grandes fracasos históricos que han demostrado los regímenes totalitarios, han surgido una vez más en Suramérica nuevos regímenes de esta clase que ahogan todas las potencias humanas. No hemos vivido en plenitud el Estado de Derecho, y surgen ya, con el aplauso de numerosos sectores, gobiernos no solo dictatoriales sino omnipotentes que están conduciendo a sus pueblos a situaciones de verdadera postración, con el agravante de que, por medio de amañadas reformas a la Constitución, y forzado culto a la personalidad, pretenden eternizarse en el poder.

Vale la pena recordar, sobre este punto, que la alternancia y la alternabilidad han constituido durante mucho tiempo un paradigma inviolable. Ahora resulta que, en un inconfesable giro de timón, lo democrático es la reelección eterna, mientras que la limitación de los periodos de gobierno no es más que una liviandad burguesa y reaccionaria.

No pensaban así nuestros héroes del 2 de abril de 1944 cuando se insurreccionaron contra el dictador Maximiliano Hernández Martínez; y menos el pueblo entero cuando por 
medio de la célebre "Huelga de brazos caídos", del 5 al 9 de mayo, terminó por derrocar al gobernante que había prolongado su usurpación por 13 años: una minucia si los comparamos con los estándares actuales en los que los gobernantes se acercan a los sesenta años de aplicación de una mano tiránica y voluntariosa sin margen para la más mínima protesta. Nuestra actual Constitución mantiene, afortunadamente, el paradigma de la alternancia. ${ }^{8}$

Estrechando más el foco para examinar los acontecimientos de larga data ocurridos en nuestro país, conviene recordar que, aun cuando el siglo XX nació bajo el impulso de las ideas renovadoras de "los cuarenta y cuatro", movimiento que, en 1894, dio nombre a la ciudad heroica, derrocando a la dictadura bicéfala de los hermanos Carlos y Antonio Ezeta, la meta del Estado de Derecho no se ha podido alcanzar.

Luego del régimen benéfico del doctor Manuel Enrique Araujo, no tardó en aparecer la dinastía Meléndez Quiñonez de ingrata recordación. Un respiro democrático constituyó el gobierno del doctor Pío Romero Bosque, que permitió las primeras elecciones libres que llevaron al poder al ingeniero Arturo Araujo con la suprema ayuda del maestro Alberto Masferrer, quien proclamaba el Mínimum Vital como un imperativo ético de la civilización. Luego, la larga noche de 50 años de gobierno militar, después de los cuales - era inevitable- estalló la cruenta guerra civil.

No hay experiencias que valgan para las duras testas de nuestros políticos, embriagados por el fanatismo de sus respectivas ideologías. Un bipolarismo extremo que ha asfixiado otras opciones se apoderó del país en una interminable guerra fría sin cuartel.

Los primeros triunfadores, después de jurar la paz y la inclusión, gobernaron para el sector económico más poderoso de la nación, aproximándose a lo que podríamos llamar una plutocracia.

En el otro extremo, los segundos, igualmente radicales, depuraron sus cuadros hasta conquistar la hegemonía y la exclusividad del movimiento insurgente, con un desenfrenado populismo y clientelismo, en ostentosa comunión con el socialismo del siglo XXI, aproximándose a lo que podríamos llamar oclocracia.

¿Qué nos depara el futuro? ¡Cuánta falta nos haría una pitonisa que, como en la antigua Grecia, nos predijera un alentador porvenir!
Pero el cielo está nublado. Y corremos sin rumbo hacia el abismo. A menos que la cordura y el coraje de nuestro pueblo recoja de nuevo, como Sísifo, la enorme peña que por enésima vez hay que subir a la montaña.

Al escribir estas líneas, leo en uno de los medios escritos de nuestro país lo siguiente: "El Directorio Ejecutivo del Fondo Monetario Internacional (FMI) alertó ayer que la dinámica de la deuda pública salvadoreña es insostenible, y alertó que las presiones sociales y políticas están atrasando la adopción de medidas encaminadas a ajustar las finanzas públicas. Así, según las proyecciones del Fondo, la deuda pública del Sector Púbico No Financiero (SPNF), incluyendo los compromisos externos del Banco Central de Reserva (BCR), representarán, al cierre de este año (2014), el 60\% del Producto Interno Bruto (PIB) salvadoreño, 2.7 puntos más que en 2013. El ratio de la deuda se elevaría al 61.9\% en 2015 y alcanzaría el 70\% en 2019, añadió el reporte. El déficit fiscal se reduciría apenas 0.1 puntos en 2014, hasta el $4 \%$ del PIB, pero en 2015 se prevé un incremento hasta del 4.4\%. Los ingresos tributarios, por su parte, se mantendrán en $15.2 \%$ en 2014 y 2015. De hecho, para este año se prevé una reducción de 0.2 puntos respecto a 2013. La dinámica de la deuda pública se está volviendo insostenible, los déficit fiscales y la cuenta corriente externa aumentaron, y las necesidades brutas de financiamiento son elevados alertó el Directorio Ejecutivo" (Diario El Mundo, 2012).

Si a los datos anteriores, de por sí escalofriantes, añadimos la corrupción galopante que padece el país y el invasivo ataque de las llamadas "maras", vinculadas con el narco tráfico, no es posible eludir, en efecto, el calificativo de "Estado fallido", que desde varias vertientes ha sido aplicado a El Salvador.

El día treinta de marzo del año dos mil once, el presidente de la República, Mauricio Funes Cartagena, sancionó la Ley de Acceso a la Información Pública, normativa que fue impulsada desde mucho antes por diferentes organizaciones de la sociedad civil, organizadas en lo que se llamó "Grupo Promotor de la Transparencia". La ley - que en todo caso constituye una conquista popularfue, sin embargo, recortada y modificada en varios trayectos de su proceso oficial de formación.

En efecto, el proyecto que conoció la Asamblea Legislativa tenía por nombre "Ley de Transparencia y Acceso a la Información Pública". Esa denominación fue recortada para dejarla con el nombre actual de "Ley de Acceso a la Información Pública", y muchas de sus disposiciones

\footnotetext{
${ }_{8}^{8}$ Constitución de la República de El Salvador, 1983, Art. 154
} 
más importantes fueron cambiadas o suprimidas. La desaparición en el título de la palabra transparencia privó a la ley de la obligación de proporcionar de oficio una información importante y de avanzar hacia una rendición de cuentas de los funcionarios públicos. El Instituto de Acceso a la Información Pública, por otra parte, integrado por cinco comisionados y sus respectivos suplentes, es nombrado, según la ley, por el Presidente de la República, en vez de serlo de forma pluri-institucional, como lo preveía el proyecto, para mencionar algunos ejemplos. $Y$, en la práctica, el funcionamiento no solo del instituto sino de todos los organismos que vertebran la institución, han sido afectados o desatendidos varias veces sin causa justa. La Asamblea Legislativa, por ejemplo, se ha negado a proporcionar el listado de sus asesores y colaboradores.

De este modo, la corrupción ha llegado a niveles tan elevados como la criminalidad, con características y consecuencias verdaderamente alarmantes, sin que hasta esta fecha se conozca un plan de combate verosímil y bien estructurado, sobre bases científicas y no empíricas u ocasionales.

Para enfrentar la apremiante situación que sufre El Salvador, solo hay dos caminos: a) una dictadura férrea que con mano dura aplique los correctivos que sean necesarios; o 2) la aplicación exacta del Estado Democrático Constitucional de Derecho.

Si bien comienzan a oírse voces que claman por la primera solución y hasta invocan el ejemplo de la administración del general Maximiliano Hernández Martínez, ya hemos expresado nuestras críticas a "los gobiernos de los hombres".

Luego, solo queda la enérgica aplicación del "Estado de Derecho" que, en esencia, no es un régimen débil sino está dotado de la coercibilidad necesaria para hacer cumplir las normas que lo caracterizan.

Cabe aquí hacer un forzosa aclaración: con frecuencia se oye a algunos dirigentes políticos afirmar, sin mayor análisis, que todos los regímenes son "de derecho", puesto que todos los países tienen leyes. Esta afirmación es errónea y nos llevaría a una prolongada discusión sobre un tema de filosofía jurídica que excede los límites del presente trabajo. Nos basta con negarla y expresar que las leyes son meramente instrumentales y pueden contener verdaderas monstruosidades, como ha quedado claramente demostrado con los regímenes totalitarios que surgieron en Europa en el siglo XX, y los que han emergido en el siglo XXI.

\section{Características de un Estado de Derecho}

Las leyes no agotan el Derecho. Este tiene más e insustituibles componentes: valores (justicia, libertad y orden), y componentes históricos y sociológicos, además de potencias inherentes al hombre, como son los derechos fundamentales.

Para esquematizar, diremos que un Estado de Derecho tiene las siguientes características:

- Soberanía popular.

- Sufragio universal y pluralismo político.

- Orden constitucional y sometimiento a la ley de gobernantes y gobernados.

- División de poderes.

- Régimen de libertades.

- Respeto a los derechos fundamentales del hombre y de la mujer.

- Transparencia en las actuaciones de los servidores públicos.

- Persecución del interés general o bien común.

A lo largo del siglo XIX florecieron dos escuelas de Derecho que se han tornado clásicas: 1) la escuela histórica; y 2) la escuela de la Jurisprudencia Sociológica.

El padre de la primera fue el jurista alemán Friedrich Karl Von Savigny, cuya obra fundamental fue De la misión de nuestro tiempo para la legislación y la ciencia del derecho. Nacido en Fráncfort del Meno, el 21 de febrero de 1779, y fallecido en Berlín el 25 de octubre de 1861. Defendió "el espíritu de los pueblos" (volkgeist) como manifestación de una comunidad concreta nacida de sus usos y costumbres, frente a la pretensión reinante de la concepción de una codificación unificada, aplicable de forma general, válida para el conjunto de la humanidad, al estilo del "Tratado de la Paz Perpetua" de Immanuel Kant.

Por el contrario, otrojuristaalemán, Rudolf Von Ihering, nacido en Aurich, Hanóver, el 22 de agosto de 1818 y fallecido en Gotinga, el 17 de septiembre de 1892, fundador del método teleológico, ha sido llamado "el padre de la jurisprudencia sociológica", y sustentó la tesis de que el derecho vale por los fines que persigue. Sus obras fundamentales fueron $\mathrm{El}$ espiritu del Derecho Romano, en la cual, más que detenerse en un examen detallado, desentrañaba la esencia de las normas jurídicas, perdurables en el tiempo; y, sobre todo, El fin del derecho, en la que sostiene que la lucha por el derecho es un deber ético. De él son estas vibrantes palabras: 
La idea del derecho encierra una antítesis que nace de estas ideas de la que es completamente inseparable: la lucha y la paz; la paz es el término del derecho, la lucha es el medio para alcanzarlo... se podrá objetar que la lucha y la discordia son precisamente lo que el derecho se propone evitar, porque semejante estado de cosas implica un trastorno, una negación del orden legal, y no una condición necesaria de su existencia. La objeción podría ser justa si se tratase de la lucha de la injusticia contra el derecho; pero aquí se habla de la lucha del derecho contra la injusticia. Si en esta hipótesis el derecho no lucha, es decir no hace una heroica resistencia contra aquella, se negaría a sí mismo. Esta lucha durará tanto como el mundo, porque el derecho habrá de prevenirse siempre contra los ataques de la injusticia. La lucha no es, pues, un elemento extraño al derecho antes bien es una parte integrante de su naturaleza y una condición de su idea. Todo derecho en el mundo debió ser adquirido por la lucha; esos principios de derecho que están hoy en vigor ha sido indispensable imponerlos por la lucha a los que no los aceptaban, por lo que todo derecho, tanto el derecho de un pueblo como el de un individuo supone que el individuo y el pueblo están dispuestos defenderlos.

El Estado de Derecho está íntimamente ligado con el sistema democrático. Pero aquí surge una grave dificultad porque todos los gobiernos, aún los más antagónicos, se proclaman democráticos, conscientes de que la democracia ha venido ganando su lugar en la historia después de vencer regímenes políticos en los cuales la voluntad popular estaba postergada.

En un libro que se ha vuelto clásico - La democracia y sus críticos-, el profesor emérito de ciencias políticas de la Universidad de Yale, Robert A. Dahl, expresa estas elocuentes palabras:

Hoy la idea de la democracia goza de universal popularidad. La mayoría de los regímenes políticos aducen algún tipo de títulos para hacerse acreedores al nombre de "democracia", y los que no lo hacen, suelen insistir en que su caso particular de gobierno no democrático es una etapa indispensable en el camino hacia la "democracia" que en última instancia es su objetivo. Hasta los dictadores parecen creer en nuestros días que adoptar una o dos pinceladas de lenguaje democrático es un ingrediente imprescindible para su legitimidad (Dahl, $\mathrm{s} / \mathrm{r}$ ).

Para simplificar las causas de esta ubicuidad diremos que, por lo menos, existen tres clases de democracia: directa, participativa y representativa, las cuales invocan sus respectivos títulos para utilizar ese nombre. La democracia directa era posible en el ágora de Atenas, pero viendo hacia el futuro acaso se renueve su posibilidad mediante el uso virtual de las redes sociales. La participativa, que se lleva a cabo mediante plebiscitos y referendos, es aceptable para algunos casos especiales, como hemos ejemplificado arriba con la disposición de la Constitución nacional que la contiene. $Y$ la representativa, es la que establece nuestra Constitución "como regla general, y se realiza mediante el sufragio periódico". De modo que el simple calificativo de democrático es un adjetivo genérico al cual le hace falta una diferencia específica para "retratar" con propiedad a qué clase de gobierno nos referimos, sin perjuicio de la legítima reserva mental que nos autoriza a distinguir la palabra enunciada y la realidad practicada. En todo caso, nuestro paradigma, vencidos todos los obstáculos, sigue siendo el Estado Democrático Constitucional de Derecho, cuya función social nos permite agregarle el cognomento de "Promotor del bien público".

Por último, afirmamos que la insignificancia internacional de los países de Centroamérica solo tiene una solución: la integración; y no solo la integración económica, sino la política, tal como nacimos a la vida independiente.

Como hemos afirmado, cuatro intentos de unión hemos tenido a lo largo de nuestra historia sin contar con las llamadas "Bases de la Constitución Federal" aprobadas el 17 de diciembre de 1823. Con fundamento en ellas, los representantes del pueblo de Centroamérica, congregados en Asamblea Nacional Constituyente, decretaron el 22 de noviembre de 1824 la primera Constitución Federal denominando a la nueva República "Federación de Centroamérica", compuesta por los estados de Costa Rica, Nicaragua, Honduras, Guatemala y El Salvador. El 13 de febrero de 1835 se dictaron reformas a la primera Constitución, equivalentes a una nueva, sin que se haya podido detener el colapso de la primera República Federal, que se produjo, finalmente, en 1838. Un nuevo intento de unión se realizó produjo en 1898, entre los Estados de Honduras, Nicaragua y El Salvador, los cuales constituyeron los "Estados Unidos de Centroamérica", sin que la unión pudiera consolidarse. Finalmente, un nuevo intento se produjo el 9 de septiembre de 1921, entre los representantes de Guatemala, Honduras y El Salvador, quienes decretaron la constitución de la República de Centroamérica de efímera duración.

Precluidos los intentos políticos constitucionales, se suscribió en 1951 la Carta de San Salvador; y sus aspectos económicos se normaron en el Tratado General de Integración Económica Centroamericana de 1960. 
Pero, a pesar de todos esos intentos y otros posteriores, que sería prolijo enumerar, el tema de la integración política, organizada como un nuevo Estado unitario o federal, precedido tal vez por una confederación, ha venido perdiendo fuerza, al grado que se ha tornado en una utopía de mayor complejidad que el Estado de Derecho.

$\mathrm{Y}$, sin embargo, desde un punto de vista racional, para acercarnos a una economía de escala, y aproximarnos a una presencia internacional significativa, la unión centroamericana, cuyo estandarte solo levantan en la actualidad algunas personas ilusas cuyos pregones son vistos con total desinterés, sigue siendo un desiderátum formidable.

\section{Conclusiones}

- Esurgentequelospartidospolíticosseorganicen"sujetándose a los principios de la democracia representativa"

- Es urgente que el Tribunal Supremo Electoral cumpla estrictamente todas las funciones que, le otorga la Constitución.

- Es urgente que la Asamblea Legislativa ejerza sus atribuciones, apartándose de banderitas partidarias y pensando en el interés general.

- Es urgente elevar el nivel cívico y cultural de nuestro pueblo a través de una educación en la que el ejemplo de los gobernantes sea el principal instrumento.

- Es urgente afirmar y consolidar una cultura de respeto a las decisiones de las instituciones de los tribunales de justicia.
- Es urgente distender el clima de polarización política en procura de una administración incluyente que conduzca a la meritocracia del sector público.

- Es urgente atender rigurosamente los dictados de la Ley de Acceso a la Información Pública y demás instrumentos legales que combaten la corrupción de los servidores públicos.

- Es urgente depurar y mejorar la Policía Nacional Civil y dotarla de más y mejores recursos, así como a la Fiscalía General de la República.

- Es urgente trazar un plan científico de combate a la criminalidad.

- Es urgente tomar conciencia de la necesidad de convertir en realidad los dictados de un Estado Democrático Constitucional de Derecho en contra de otros sistemas de organización política.

- Es urgente la cooperación de todos los sectores de la sociedad para superar la crisis que actualmente sufre nuestro país. "La triple hélice del desarrollo" — gobierno, empresa y universidad - es la mejor vía para el progreso y el desarrollo de nuestro pueblo.

\section{Referencias}

Diario El Mundo (marzo de 2012)

Aristóteles (s/r). La política. Capítulo V.

Constitución de la República de El Salvador (1983). El Salvador: Fespad.

Dahl, R.A. (s/r). La democracia y sus críticos. Barcelona. Loewestein, K. (s/r). Teoría de la Constitución.

Rousseau, J.J. (s/r). El contrato social. 